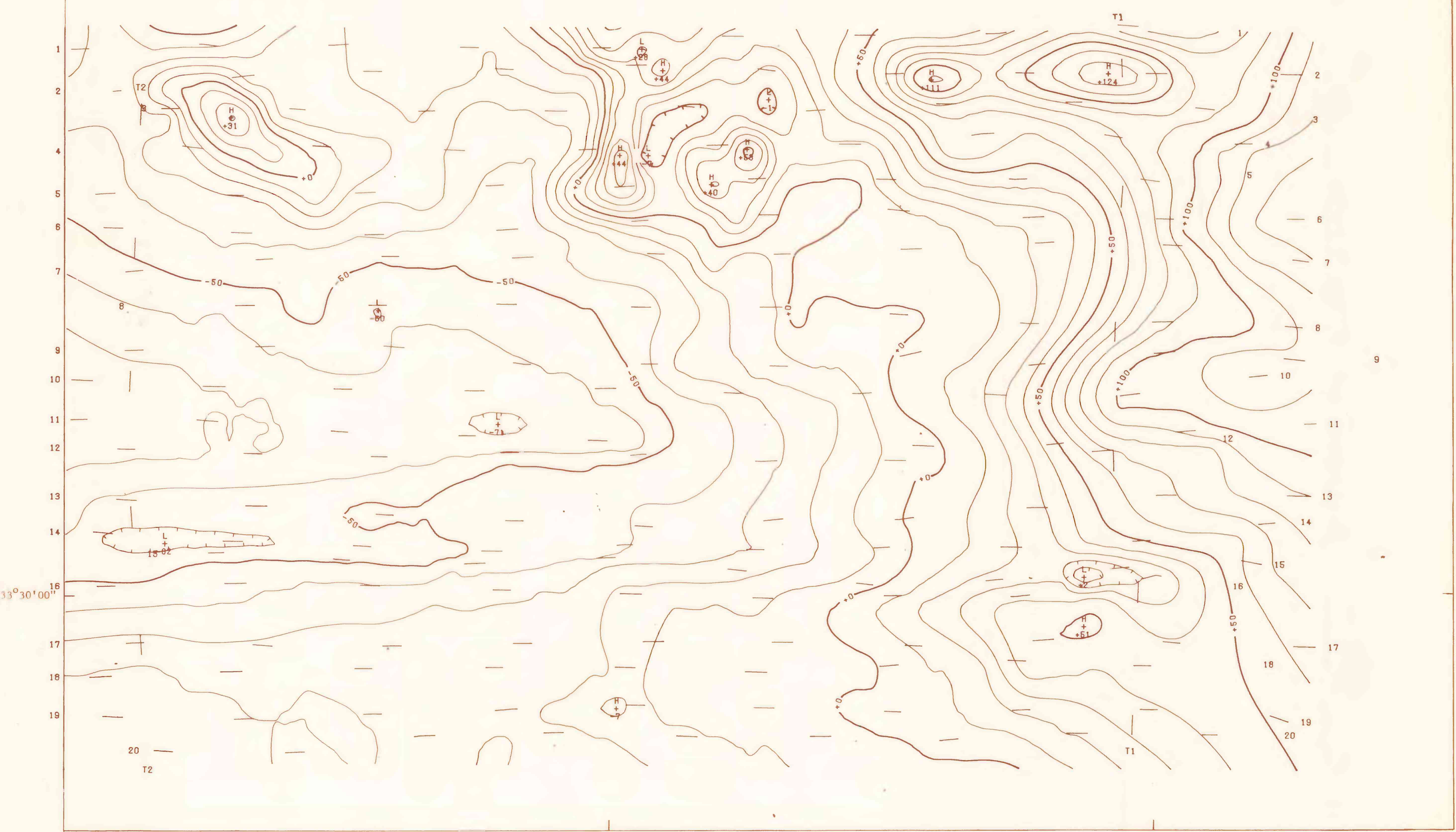

\title{
AEROMAGNETIC MAP OF THE
}

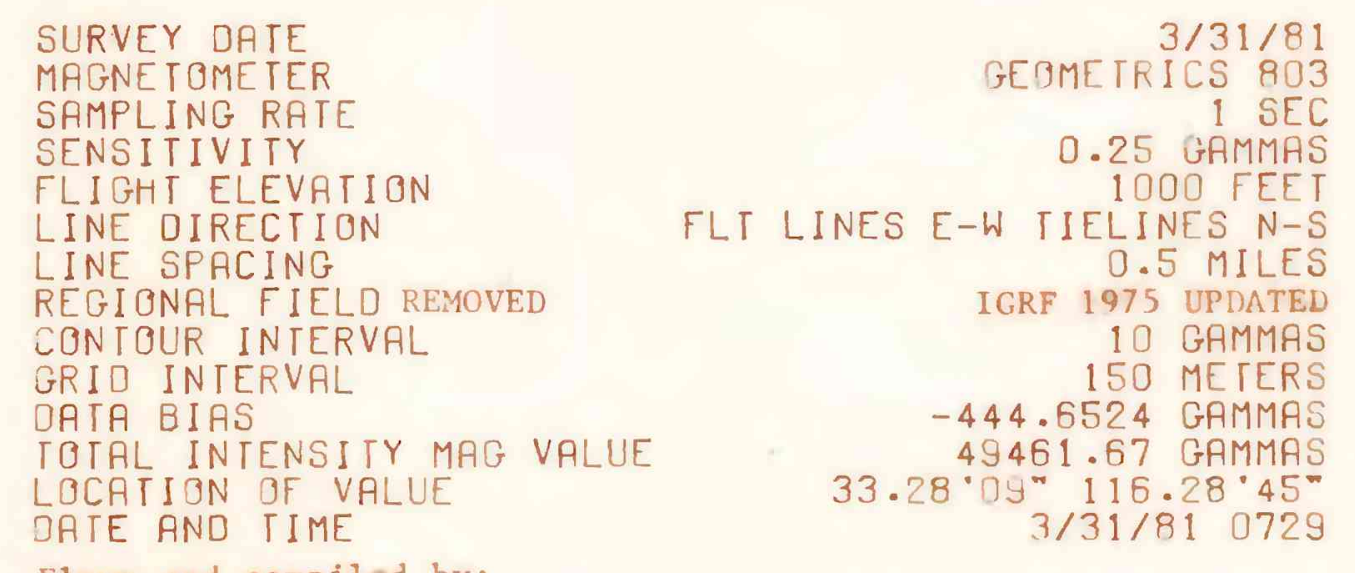

CACTUS SPRINGS AREA, CALIFORNIA High Life - QEB, Inc.

BY

U.S. GEOLOGICAL SURVEY

198

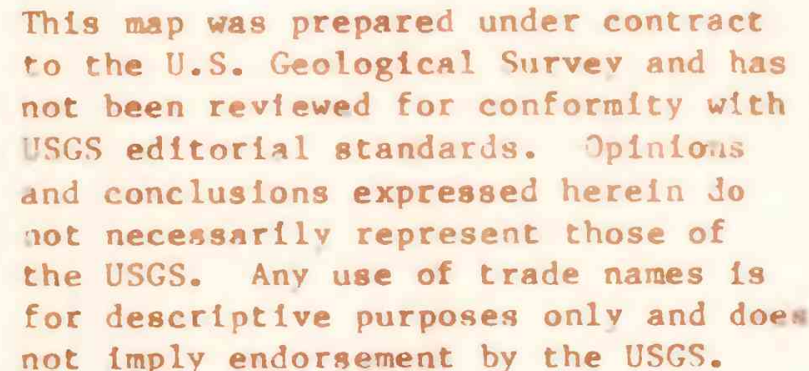

\section{SCALE I:62,500}

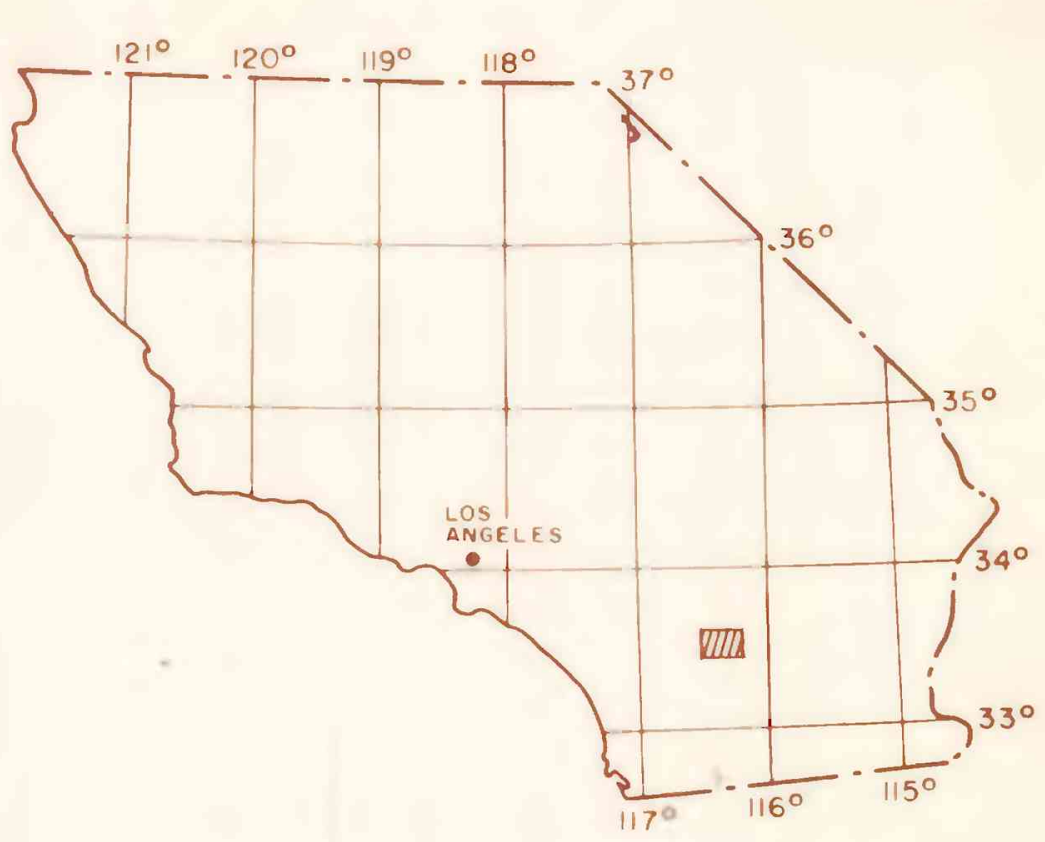
INDEX MAP OF SOUTHERN CALIFORNIA 